\title{
Atendimento pessoal ao jurisdicionado litigante pelo magistrado tocantinense
}

Costumer service to the litigant jurisdictionate by the Tocantins' magistrate court

Rafael Giordano Gonçalves Brito Universidade Federal do Tocantins

Rodrigo da Silva Perez Araúuo Universidade Federal do Tocantins

Patrícia Medina Universidade Federal do Tocantins

Gustavo Paschoal Teixeira de Castro Oliveira Universidade Federal do Tocantins

\section{INTRODUÇÃo}

A presente resenha versa sobre artigo e dissertação de mestrado pelo qual se sintetizou investigação a respeito do desempenho do Poder Judiciário quanto ao seu papel social apaziguador, consistente no atendimento extraprocessual às partes pelo magistrado em seu gabinete. Compreendido como dimensão do direito humano fundamental de acesso à justiça, positivado no Artigo 35, IV, da Lei Complementar $n^{\circ}$. 35, de 1979 - também conhecida como Lei Orgânica da Magistratura Nacional (LOMAN) - e no Código de Ética da Magistratura, e que, na opinião de Iglesias e Medina (2015), ocorreria de maneira diversificada e pouco satisfatória. 
Compreende que o atendimento às partes diretamente pelo juiz realizaria objetivo posto pelo Conselho Nacional de Justiça (CNJ), de aproximação do Poder Judiciário à população, gerando transparência, confiabilidade e segurança.

Como problema de pesquisa, propôs-se investigar como esse atendimento vem sendo realizado no Judiciário Tocantinense e, como objetivo, aventou aperfeiçoamentos para incentivar que a prática se dê com respeito aos direitos e garantias relacionados.

\section{Desenvolvimento}

A pesquisa de Iglesias e Medina foi realizada mediante revisão bibliográfica, análise de decisões judiciais e da legislação incidente, além de pesquisa empírica levada a cabo mediante aplicação de questionários semiestruturados, em 2014, em todas as unidades jurisdicionais do Estado do Tocantins. Buscou identificar: os procedimentos usados pelos juízes estaduais para a realização do atendimento às partes; como esse atendimento preservava sua produtividade, o contraditório e a imparcialidade; os benefícios trazidos para a resolução do conflito; e a opinião dos envolvidos. Entretanto, apenas 65 magistrados e 22 jurisdicionados responderam.

Constataram, quanto a esses, receio de possíveis interferências no resultado de suas demandas, além de confusão entre o atendimento analisado e a própria audiência; em relação aos primeiros, aqueles mais antigos e de mais idade tiveram resistência em responder.

As respostas foram transcritas e submetidas a análise lexical e de conteúdo para a formação de categorias de conteúdo mais gerais, com o que pretenderam obter os aspectos mais relevantes evocados nas respostas, os quais, ao final, foram submetidos a reflexão.

\section{ApresentaÇão dos resultados e discussão final}

Após discorrerem sobre conceitos prévios necessários à compreensão do estudo por qualquer interessado, ainda que não introduzido ao 
Direito, concluíram que "as pretensões dos jurisdicionados com relação ao atendimento são extremamente particulares, mas algumas foram repetidamente citadas na pesquisa realizada" (IGLESIAS e MEDINA, 2015, p. 545), conforme se depreende da Figura 1.

Figura 1 - Pretensões dos jurisdicionados quanto ao atendimento.

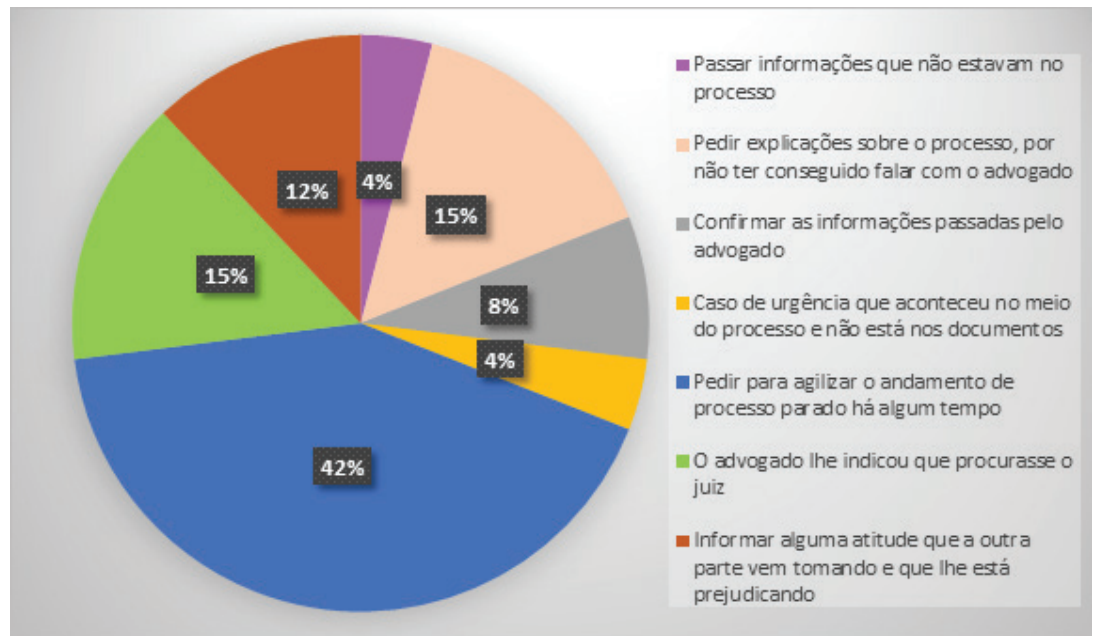

Fonte: IGLESIAS, 2015a, p. 21 (com adaptações).

A previsão legal do atendimento investigado seria lacunosa, na medida em que ele é imposto apenas quanto aos casos que possibilitem solução de urgência e sem forma definida.

Iglesias e Medina (2015) deduziram que essa circunstância e a falta de informação pelos jurisdicionados são determinantes para que $20 \%$ dos magistrados atendam às partes apenas nos casos que julgam urgentes, sendo que, desses, 7\% somente o fazem na presença do advogado da parte. Reputam, portanto, indevido e implica que 3\% dos magistrados nunca atendem às partes. Por sua vez, 78\% dos juízes atendem a todos que os procuram.

Quanto aos jurisdicionados, 55\% buscaram atendimento, dos quais $75 \%$ foram atendidos. Desses, $20 \%$ desconheciam a possibilidade, ou- 
tros $20 \%$ declararam desconfiar da eficiência do atendimento e $17 \%$ relataram não serem atendidos se desacompanhados de seus advogados.

Ponderaram que a negativa de atendimento não determinaria qualquer providência por parte do jurisdicionado, seja por temor de represália, seja porque a conversa não seria produtiva, o que justificaria a inexistência de estudos específicos.

Verificaram que o atendimento é bem visto pelos pesquisados, pois $65 \%$ dos magistrados e $73 \%$ dos jurisdicionados são favoráveis.

Argumentaram que, além de aceito, o atendimento às partes realiza a função social do Poder Judiciário ao concretizar uma dimensão do direito humano fundamental do acesso à justiça concernente à geração de tranquilidade entre os envolvidos, transparência e aproximação. Com efeito, culminará na valorização institucional, desde que efetuado em consonância com o contraditório, a imparcialidade do juiz e a duração ótima do processo.

Como perspectivas interdisciplinares, Iglesias (2015) elegeu a fenomenologia do cuidar, da obra "Ser e tempo" (1927) de Martin Heidegger, ligada à Filosofia, e Administração Pública.

Quanto à esfera administrativa, asseveraram ser a prestação jurisdicional modalidade de serviço público e, por isso, regida pelos princípios da Administração Pública, notadamente: segurança, somente alcançada pela qualidade do serviço e pela gravação do atendimento para a preservação do jurisdicionado e do magistrado, com possibilidade de disponibilização à parte contrária; eficiência, a ser alcançada pela divulgação da possibilidade, padronização, registros dos pedidos, para controle e acompanhamento, agendamento de horários, e redução da amplitude interpretativa do preceito legal que prevê o atendimento.

A nosso ver, em uma perspectiva jurídica da Administração Pública, é salutar que o atendimento pessoal ao jurisdicionado pelo magistrado está alicerçado no princípio da moralidade ${ }^{1}$ administrativa, pois trata

\footnotetext{
Para Medina (2011, p. 88-89), “A moralidade independe de fronteiras geográficas, constituiu regras que as pessoas assumem para garantir um bem-viver ou uma identidade grupal e social, mesmo que elas não se relacionem, tenham afinidade ou que sequer se conheçam. Pode-se expressar concretamente como quando os homens aca-
} 
do cuidado com a res publica. Isto é, o bom administrador, não somente deve ser conhecedor da lei, mas também dos princípios éticos regentes da função administrativa. "Cumprir simplesmente a lei na frieza de seu texto não é o mesmo que atendê-lo na sua letra e no seu espírito", por isso a Administração “[...] deve ser orientada pelos princípios do Direito e da Moral, para que ao legal se ajunte o honesto e o conveniente aos interesses sociais", incluindo aí, por óbvio, o do jurisdicionado (MEIRELLES, 1998, p. 94).

No que tange à fenomenologia do cuidar, alegaram que toda presença-existência pertence à cura, relaciona-se à coexistência - necessária, porque o homem só existe se conhece e se desenvolve enquanto pessoa em face de outro -, logo "[...] todo o comportamento humano se concretizará pelo cuidado" (IGLESIAS, 2015, p. 83), na medida em que o mundo é construído a partir de laços afetivos, sendo essa a essência do cuidar; cuidado esse que, segundo Boff (1999), imprescinde da capacidade de simpatia, empatia, dedicação e comunhão com o próximo, além da escuta pautada nas ideias de atenção e consideração.

Para Heidegger (2005, p. 257), “a cura não indica, portanto, primordial ou exclusivamente, uma atitude isolada do eu consigo mesmo. A expressão 'cura de si mesmo', de acordo com analogia de ocupação e preocupação, seria uma tautologia", pois somente assim o escutar torna possível o ouvir. ${ }^{2}$ Com efeito, toda vez que se escuta atentamente al-

tam os costumes de determinada região quando migram como trajar uma determinada indumentária ou guardar o dia de um determinado santo. O Direito, por sua vez, institui o regramento social, delimitando as fronteiras geográficas territoriais, pois se materializa na forma de leis e estas têm vigência dentro de determinado território. [...] O momento histórico que a humanidade vive genericamente denominado crise é de ordem ético-moral, pois envolve o agir, mas também avança sobre o existir. Destaca-se a preocupação da avaliação sobre os resultados". Indaga-se, portanto, se seria em busca desses resultados (também postos pelo Conselho Nacional de Justiça) que os magistrados deixam de atender aos magistrados em seus gabinetes?

2 Embora aqui não esteja se tratando da compaixão do magistrado para com o jurisdicionado, é possível fazer uma analogia ao comportamento e atitude do ouvir na Bíblia Sagrada (2010, p. 1.299-1.300), mais precisamente na Parábola do Semeador (Mateus 13: 9, 13-16, 23), isto é, somente aquele (o bem-aventurado) que escuta e coloca em prática o ensinamento poderá colher bons frutos. 
guém que nos fala, fará que esse se encontre junto daquilo sobre o que se fala.

A falta de cuidado pelo prestador do serviço público compromete, nessa medida, as boas relações humanas e jurisdicionais, não apazigua os conflitantes, comprometendo as relações sociais e, por conseguinte a produtividade em razão da geração ou da perpetuação do conflito. Daí, afirmar que a conciliação está relacionada com a fenomenologia do cuidar, uma vez que permite as partes em comum acordo - escutando, ouvindo e se conhecendo - não apenas pôr fim a um processo, mas, sobretudo, alcançar a pacificação social. Nesse sentir, Sampaio Júnior (2007, p. 177) afirma que a utilização da conciliação, por exemplo, se bem explorada pelo juiz, pode "[...] descobrir os conflitos reais e, assim, obter a sonhada pacificação substancial do conflito, estimulando, muitas vezes, a uma nova amizade ou, até mesmo, reconciliações, que a sentença nunca conseguiria [...]". Ainda, segundo esse autor, trata-se de descaso com a função pública nos casos em que pensa a atividade jurisdicional sem visar, obrigatoriamente, a pacificação social, de tal modo que vai de encontro com o objetivo posto pelo $\mathrm{CNJ}$ : aproximação da sociedade ao Poder Judiciário.

Conclui por alegar que a pessoalidade gerada pelo atendimento contribui para que se leve a sério o ato de julgar, haja vista a "personificação" dos sujeitos processuais. Entendemos, portanto, oportuno citar a lição de Bauman (2014), quando afirma que as pessoas não devem ser vistas apenas como números, é necessário enxergar a tragédia ${ }^{3}$ que

3 Em tempos de uma sociedade voltada para o consumismo, Bauman (2014, p. 26) afirma que as experiências traumatizantes, tidas "[...] como um monstro interior em nossa era líquida moderna ou nos períodos sombrios, em que mais frequentemente nos recusamos a garantir a existência do Outro, ou a vê-lo e ouvi-lo, em vez de oferecer uma ideologia canibal? Tendemos a substituir a situação existencial olho no olho e face a face, por um sistema classificatório abrangente, que consome vidas e personalidades humanas como dados empíricos e evidências ou estatísticas”. O autor (2014, p. 16) entende ainda que "o mal não está confinado às guerras ou ideologias totalitárias, Hoje ele se revela com mais frequência quando deixamos de reagir ao sofrimento de outra pessoa, quando nos recusamos a compreender os outros, quando somos insensíveis e evitamos o olhar ético silencioso". 
acontece com os outros, pois ela é real e pode acontecer comigo física e diretamente.

\section{REFERÊNCIAS}

BAUMAN, Zygmunt; DONSKIS, Leonidas. Cegueira moral: a perda da sensibilidade na modernidade líquida. Tradução: Carlos Alberto Medeiros, 1. ed. Rio de Janeiro, Zahar: 2014.

BÍBLIA. Português. Bíblia Sagrada: Ave Maria. Tradução dos originais grego, hebraico e aramaico mediante a versão dos monges Beneditinos de Maredsous (Bélgica). Edição atualizada Claretiana. São Paulo: Ave Maria, 2010.

BOFF, Leonardo. Saber Cuidar: Ética Do Humano-compaixão pela terra. Petrópolis (RJ): Vozes, 1999. Disponível em: < http://www.dhnet.org.br/direitos/ militantes/boff/boff_eticahumano.html>. Acesso em: 6 out. 2017.

HEIDEGGER, Martin. Ser e tempo. Tradução de Márcia Sá Cavalcante Schuback, 15 ed. Petrópolis: Vozes, 2005.

IGLESIAS, Aline Marinho Bailão. Atendimento pessoal ao jurisdicionado litigante pelo magistrado tocantinense: uma análise à luz da função social do poder judiciário e da maximização do acesso à justiça, 2015a, 106s. Dissertação (Mestrado em Prestação Jurisdicional e Direitos Humanos) - Universidade Federal do Tocantins, Palmas, 2015. Disponível em: $<$ http://repositorio. uft.edu.br/bitstream/11612/123/1/Aline\%20Marinho\%20Bail\%C3\%A3o\%20 Iglesias\%20-\%20Disserta\%C3\%A7\%C3\%A3o.pdf>. Acesso em 8 ago. 2017.

IGLESIAS, Aline Marinho Bailão; MEDINA, Patrícia. Atendimento pessoal ao jurisdicionado litigante pelo magistrado tocantinense: proposta de melhorias à prestação jurisdicional e à formação permanente. In: XXII Congresso Nacional de Educação. Curitiba, PUCPR: 26 a 29 de out. 2015. Disponível em: <http://educere.bruc.com.br/arquivo/pdf2015/21308_9740.pdf $>$. Acesso em: 8 ago. 2017.

MEDINA, Patrícia. A Relação homem-natureza, a fenomenologia do cuidar e a dimensão formativa, 2011, 161s. Tese (Doutorado em Educação) Universidade Federal de Goiás, Goiânia, 2011. Disponível em: <https://repo- 
sitorio.bc.ufg.br/tede/bitstream/tde/1125/1/Tese\%20Patricia\%20Medina.pdf $>$. Acesso em: 19 set. 2017.

MEIRELLES, Hely Lopes; BURLE FILHO, José Emmanuel. Direito administrativo brasileiro, 42. ed. São Paulo: Malheiros, 2016.

SAMPAIO JÚNIOR, José Herval. O papel do juiz na tentativa de pacificação social: a importância das técnicas de conciliação e mediação. In: Revista Liberdade e Direito. Mossoró - v. 6, n. 2, p. 177-212, jan./jun. 2007. Disponível em: <http://www.esmarn.tjrn.jus.br/revistas/index.php/revista_direito_e_liberdade/article/download/107/99>. Acesso em 19 set. 2017.

\section{SOBRE OS AUTORES}

\section{Rafael Giordano Gonçalves Brito}

Mestrando em Prestação Jurisdicional e Direitos Humanos (UFT/Esmat). Especialista em Administração Pública e Especialista em Direito Público pela Escola Superior da Magistratura Tocantinense, ESMAT. Técnico judiciário do Poder Judiciário do Estado do Tocantins. Servidor Público no Tribunal de Justiça do Estado do Tocantins.

CV: http://lattes.cnpq.br/1684457829060648

E-mail: advrafaelbrito@gmail.com

\section{Rodrigo da Silva Perez Araújo}

Mestrando em Prestação Jurisdicional e Direitos Humanos (UFT/Esmat). Especialista em Direito civil e processual civil pela Faculdade do Grupo UNIASSELVI, FAMESUL. Juiz de Direito do Poder Judiciário do Estado do Tocantins. Juiz de Direito junto ao Tribunal de Justiça do Estado do Tocantins.

CV: http://lattes.cnpq.br/0385374879515131

E-mail: ro.zerep@gmail.com 


\section{Patrícia Medina}

Doutora em Educação: Cultura e Processos Educacionais pela UFG. Mestre em Administração de Sistemas Educacionais pela Pontifícia Universidade Católica do Rio Grande do Sul, PUCRS. Pedagoga pela Faculdade Porto Alegrense de Educação Ciências Humanas e Letras, FAPA. Bacharel em Direito pela Fundação Universidade Federal do Tocantins, UFT. Professora Ajunta da UFT nos cursos de Pedagogia e Mestrado Profissional Interdisciplinar Prestação Jurisdicional e Direitos Humanos em convênio com Escola da Magistratura do Tocantins.

CV: http://lattes.cnpq.br/2860664409387797

E-mail: patriciamedina@uft.edu.br

\section{Gustavo Paschoal Teixeira de Castro Oliveira}

Doutor em Direito das Relações Internacionais pelo UniCeub. Mestre em Direito pela Unaerp. Especialista em Direito Civil e Direito Processual Civil pela Unifran. Docente na UFT e no Ceulp/Ulbra. Coordenador do Mestrado Profissional Interdisciplinar Prestação Jurisdicional e Direitos Humanos em convênio com Escola da Magistratura do Tocantins da UFT. Advogado.

CV: http://lattes.cnpq.br/7410990226412683

E-mail: gustavopaschoal1@gmail.com

Submetido em: 16-3-2018

Aceito em: 15-5-2018 